\title{
Phytocontact dermatitis due to Ranunculus arvensis: Report of three cases
}

\author{
(D) Isa An, (D) Derya Ucmak, (D) Mustafa Esen, (D) Ozlem Devran Gevher \\ Department of Dermatology, Dicle University Faculty of Medicine, Diyarbakir, Turkey
}

\begin{abstract}
Ranunculus arvensis (R. arvensis) is a member of the Ranunculaceae family and is often used by advanced age women living in rural areas for the topical treatment of arthralgia, myalgia, hemorrhoid, and warts. Protoanemonin is a substance found in the fresh leaves of the plants from the Ranunculaceae family and leads to contact dermatitis. In this report, we present three cases that developed phytocontact dermatitis caused by the topical use of $R$. arvensis as an alternative treatment method for arthralgia and palmoplantar psoriasis.
\end{abstract}

Keywords: Contact dermatitis; Ranunculus arvensis; topical.

Cite this article as: An I, Ucmak D, Esen M, Devran Gevher O. Phytocontact dermatitis due to Ranunculus arvensis: Report of three cases. North Clin Istanb 2019;6(1):81-84.

$\mathrm{I}^{\mathrm{n}}$ n Turkey, traditional herbal remedies are widely used, both topically and systemically. The tendency of using such remedies is more frequent particularly in geriatric age. In such patients, topical use is preferred due to the anti-inflammatory effects of these remedies, particularly for myalgia and arthralgia $[1,2]$. In this report, we present three cases that developed contact dermatitis caused by the topical use of Ranunculus arvensis.

\section{CASE REPORT}

Case 1 - A 62-year-old female patient presented with bullous lesions on the right knee. The patient history revealed that the patient, following the advice of a relative, wrapped the flower named "wedding bloom" around her knee with a cloth for her long-lasting knee pain. After about $6 \mathrm{~h}$, the patient removed the cloth due to severe pain and itching and noticed the bullous lesions. The patient had no previous contact with this herb. The patient had no systemic disease except for hypertension and had no history of drug use. Skin examination revealed mul- tiple erythematous, tense bullae on the right knee (Fig. 1 ). The herb provided by the patient was confirmed as $\mathrm{R}$. arvensis by the Botany Department. A therapy including topical antibiotic, systemic methylprednisolone 40 $\mathrm{mg} /$ day, and wet dressing was initiated. All the lesions resolved within 10 days.

Case 2 - A 64-year-old male patient presented with ulcerated lesions on the right leg. Following the advice of a friend, the patient applied the wedding bloom around his leg with a cloth for his long-lasting knee and leg pain. Approximately $8 \mathrm{~h}$ later, the patient noticed the lesions when he opened the wrap due to a severe sensation of pain and burning. On dermatological examination, there were erythematous, eroded bullous lesions with crusts and ulcerated areas with a diameter of $3-4 \mathrm{~cm}$ on the right leg (Fig. 2). Laboratory parameters including whole blood count and liver functions tests were within normal ranges. The herb provided by the patient was confirmed as R. arvensis by the Botany Department. A therapy including oral antibiotic, systemic methylprednisolone 40 $\mathrm{mg} /$ day, and wet dressing was initiated. All the lesions

Received: September 17, 2017 Accepted: February 11, 2018 Online: August 07, 2018

Correspondence: Dr. Isa AN. Dicle Universitesi Tip Fakultesi, Deri ve Zuhrevi Hastalikları Anabilim Dali, Diyarbakır, Turkey.

Phone: +90 4122488001 e-mail: is_an89@hotmail.com

(c) Copyright 2019 by Istanbul Provincial Directorate of Health - Available online at www.northclinist.com 


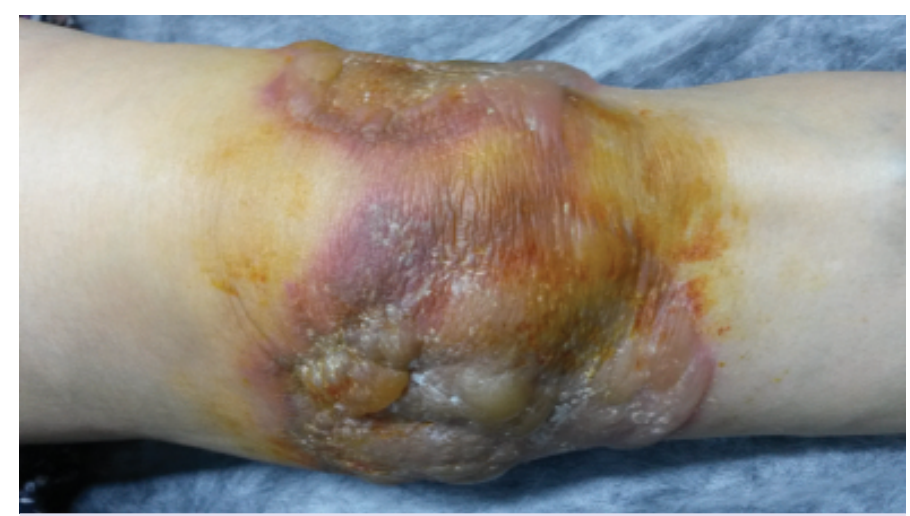

FIGURE 1. Skin examination revealed multiple erythematous, tense bullae on the right knee.

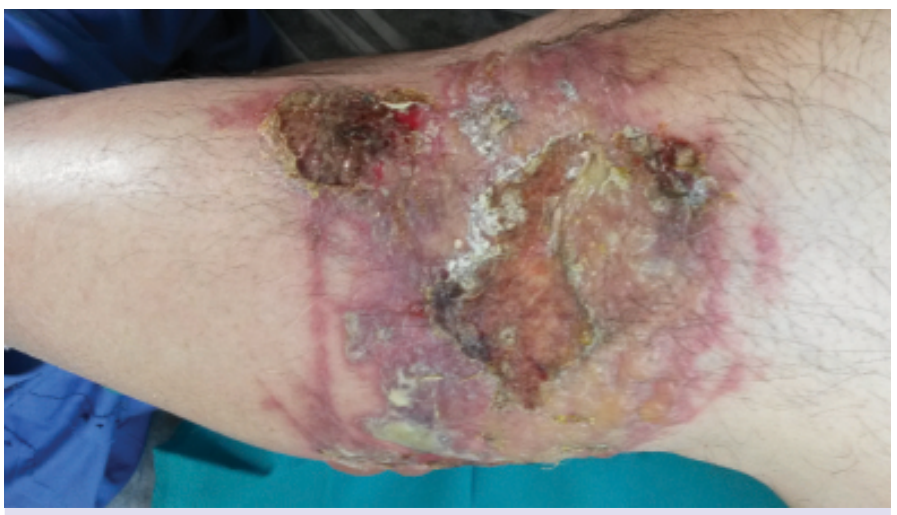

FIGURE 2. On dermatological examination, there were erythematous, eroded bullous lesions with crusts and ulcerated areas with a diameter of $3-4 \mathrm{~cm}$ on the right leg.

resolved within 2 weeks.

Case 3 - A 53-year-old male patient presented with bullous lesions in the palms and the back of the foot. The patient had been on topical steroid therapy due to palmoplantar psoriasis for the past 2 years. The patient purchased wedding bloom from a street market and wrapped the herb around his hands and feet with a cloth due to aggravating lesions. Approximately $2 \mathrm{~h}$ later, the patient noticed the bullae after opening the wrap due to a severe sensation of pain and itching. Dermatological examination revealed multiple erythematous, tense bullae in both palms, on the extensor surface of the left hand, and the extensor surface of the left foot (Fig. 3). The herb provided by the patient was confirmed as $\mathrm{R}$. arvensis by the Botany Department (Fig. 4). A therapy including topical antibiotic, systemic methylprednisolone $60 \mathrm{mg} /$ day, and wet dressing was initiated. The lesions resolved within 2 weeks.

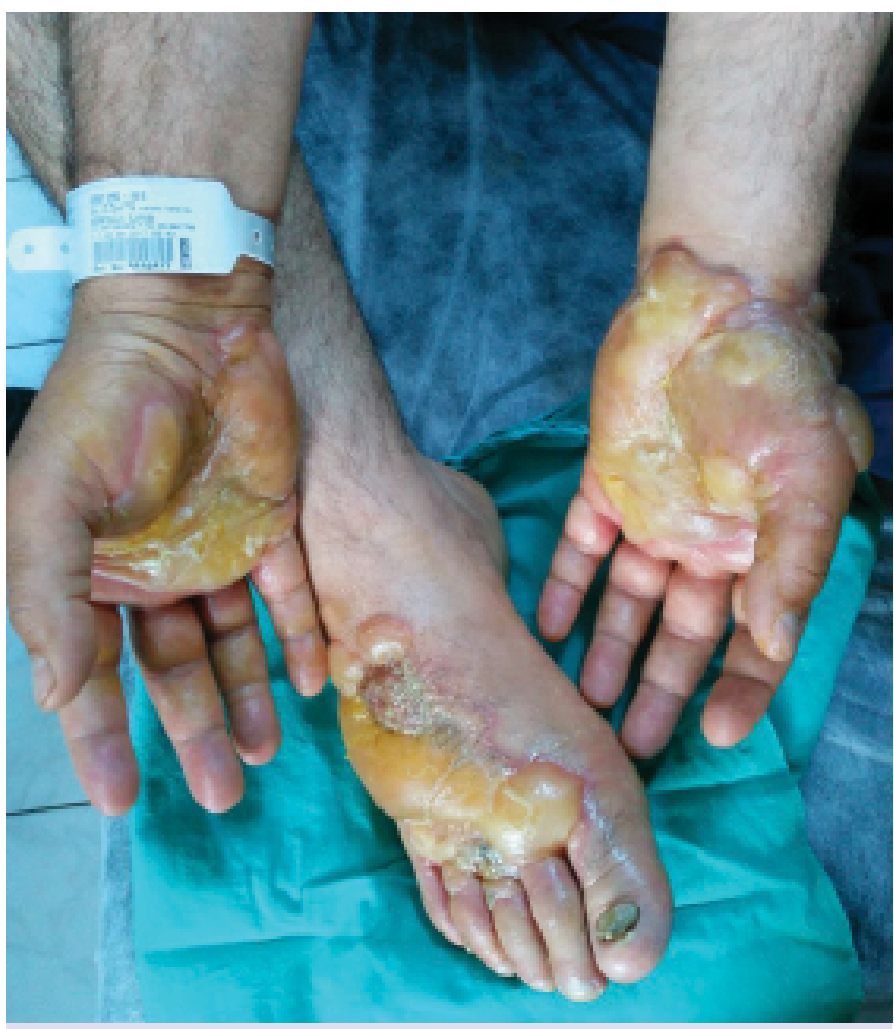

FIGURE 3. Dermatological examination revealed multiple erythematous, tense bullae in both palms, on the extensor surface of the left hand and the extensor surface of the left foot.

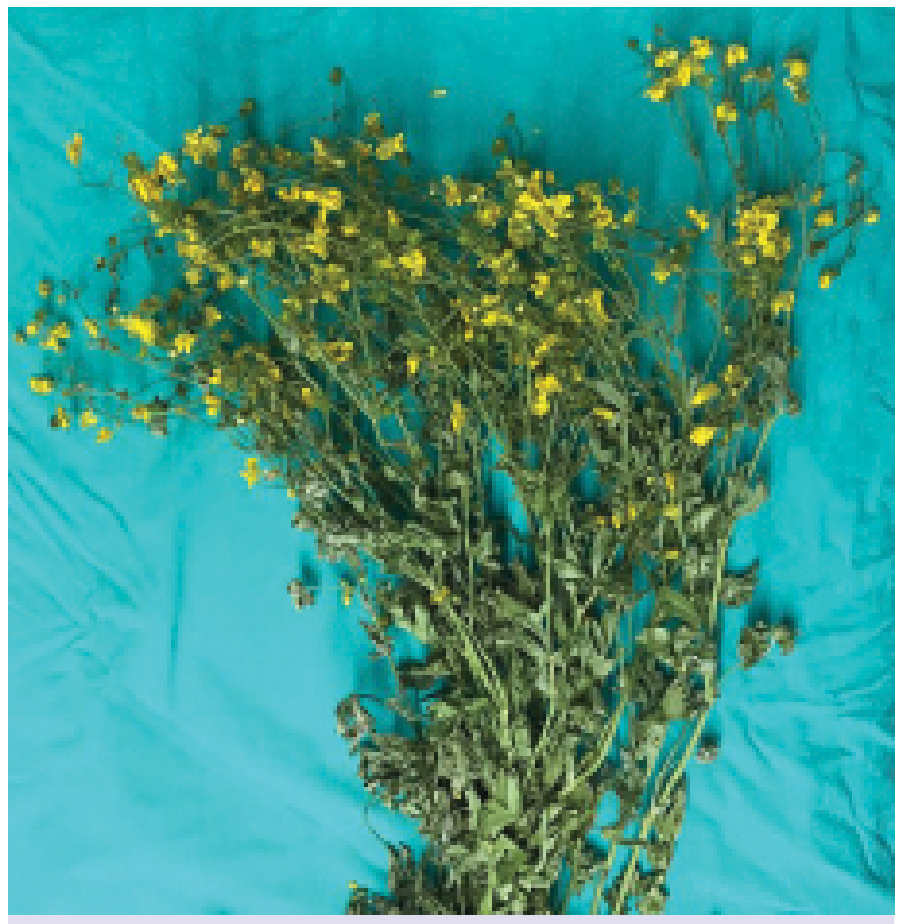

FIGURE 4. Ranunculus arvensis. 


\section{DISCUSSION}

Members of the Ranunculaceae family are herbaceous plants that have five yellow petals and are commonly seen in wet environments particularly during the spring and summer. The family has approximately 1900 species, and about 70 of them are seen in Turkey. In Turkey, R. arvensis is mostly known as "wedding bloom." [1, 3] It grows in fertile lands in the Mediterranean, Eastern Anatolian, and Southeastern Anatolian regions, mostly at an altitude of $1850 \mathrm{~m}$. Many people use R. arvensis mostly in the treatment of arthralgia, myalgia, burns, cuts, edema, drainage of abscesses, hemorrhoid, and warts $[4,5]$. In our patients, R. arvensis was used for the complaint of arthralgia and the treatment of psoriasis lesions.

Members of the Ranunculaceae family contain ranunculin which has irritant features. Ranunculin is the precursor of protoanemonin, which is known as a toxic substance and considered to be the actual cause of the toxic effect. Ranunculin is transformed to protoanemonin in case of dermal contact $[6,7]$. Protoanemonin is a volatile oil with antimycotic and antimicrobial properties and inhibits DNA polymerase by increasing free oxygen radicals. In the structure of protoanemonin, there are highly irritant lipids such as saponin, hederagenin, and oleanolic acid glycosides. When applied on the skin surface, R. arvensis causes destruction of sulfur chains, thereby leading to bullae formation and subepithelial detachment. Protoanemonin is often located in flowers and fresh leaves of the herb; therefore, the ground pieces of fresh flowers and leaves have a stronger irritating effect. However, when the herb gets withered, the irritating effect decreases to minimum because protoanemonin is transformed to anemonin, which is a harmless polymer. If digested in high amounts systemically, the plants from the Ranunculaceae family can lead to diarrhea, vomiting, hypersalivation, burning in the mouth and throat, abdominal cramps, and neurological symptoms [1, 4-6].

In a recent study reporting on 25 cases of phytocontact dermatitis caused by the species of Ranunculaceae family, Akbulut et al. [3] indicated that five cases were associated with R. arvensis. Most of the patients were middle and old age women and the authors also reported that the duration of contact with the herb ranged between 25 min and $48 \mathrm{~h}$ and R. arvensis was mostly applied on the painful extremity. The authors concluded that the degree of the severity of the injury was associated with the diameter of the contact with the herb, the duration of contact, and the herb applied.
Phytodermatitis can be divided into three subgroups including irritant contact phytodermatitis, allergic contact phytodermatitis, and phytophotodermatitis. Clinically, irritant reactions can lead to urticarial, erythematous, vesiculobullous, and chronic fissures or squamous lesions $[6,8]$. We planned to do patch test with the flowers of R. arvensis, but we could not do because the patients did not accept it. All of our cases were diagnosed as irritant phytodermatitis since the lesions occurred only in the site of application within a short period after the administration and the affected sites were not exposed to sunlight.

The primary step in the treatment of phytodermatitis is the cessation of the contact with the herb. Antihistaminic drugs including local and systemic corticosteroids can be prescribed to prevent the sense of itching. In addition, antimicrobial agents such as silver sulfadiazine, fusidic acid, chlorhexidine, povidone-iodine, and mupirocin can be used for local wound care $[1,8]$. Our cases were treated by systemic steroids, topical antibiotics, and wet dressing.

\section{Conclusion}

Plants from the Ranunculaceae family are widely seen both in Turkey and the world. Since these herbs are easily accessed and are believed to be harmless by the people living in rural areas, they will continue to be used by these people, particularly elderly people, for alternative treatment methods. These people should be informed about the potential side effects of these herbs.

Informed Consent: Written informed consent was obtained from the patients for the publication of the case report and the accompanying images.

Conflict of Interest: No conflict of interest was declared by the authors.

Financial Disclosure: The authors declared that this study has received no financial support.

Authorship Contributions: Concept - I.A., D.U.; Design - O.D.G., M.E.; Supervision - O.D.G., M.E.; Materials - O.D.G., M.E.; Data collection \&/or processing - I.A., D.U.; Analysis and/or interpretation - I.A., D.U.; Writing - I.A.; Critical review - I.A., D.U.

\section{REFERENCES}

1. Uçmak D, Ayhan E, Meltem Akkurt Z, Uçak H. Presentation of three cases with phyto contact dermatitis caused by Ranunculus and Anthemis genera. J Dermatolog Treat 2014;25:467-9. [CrossRef]

2. Karaca S, Kulac M, Kucuker H. Phytodermatitis caused by Ceratocephalus falcatus (Ranunculacea). Eur J Dermatol 2005;15:404-5. 
3. Akbulut S, Semur H, Kose O, Ozhasenekler A, Celiktas M, Basbug M, et al. Phytocontact dermatitis due to Ranunculus arvensis mimicking burn injury: Report of three cases and literature review. Int J Emerg Med 2011;4:7. [CrossRef]

4. Kocak AO, Saritemur M, Atac K, Guclu S, Ozlu I. A rare chemical burn due to Ranunculus arvensis: Three case reports. Ann Saudi Med 2016;36:89-91. [CrossRef]

5. Orak M, Ustundag M, Guloglu C, Tas M, Baylan B. A skin burn associated with Ranunculus arvensis (wedding bloom). Indian J Dermatol
2009;54:19-20. [CrossRef]

6. Polat M. A case of phytodermatitis due to Ranunculus arvensis used as an herbal remedy. Int J Dermatol 2016;55:e37-8. [CrossRef]

7. Oztas P, Gur G, Senlik B, Yalcin B, Polat M, Tamer E, et al. Phytocontact dermatitis due to Ranunculus illyricus: Two cases. J Eur Acad Dermatol Venereol 2006;20:1372-3. [CrossRef]

8. Calka O, Akdeniz N, Özkol HU, Karadag AS, Behçet L. Irritant contact dermatitis caused by Ranunculus kotschyi boiss in 6 cases. Contact Dermatitis 2011;64:174-6. [CrossRef] 